Eixo Roda, Belo Horizonte, v. 28, n. 2, p. 191-213, 2019

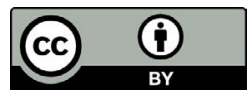

\title{
A comida paraense em Belém do Grão Pará, de Dalcídio Jurandir
}

\section{The Paraense Food in Belém do Grão Pará, by Dalcídio Jurandir}

\author{
Fabiano Dalla Bona \\ Universidade Federal do Rio de Janeiro (UFRJ), Rio de Janeiro, Rio de Janeiro / Brasil \\ fdbona@gmail.com
}

Resumo: Em Belém do Grão Pará, quarto romance do escritor marajoara Dalcídio Jurandir, grande parte da tradicional gastronomia paraense é descrita com especial atenção. Das cozinhas dos barões da borracha às comidas de rua, pode-se assistir a um desfile de iguarias que atiçam o paladar, a visão, o tato e a audição, entre exotismo e tradição.

Palavras-chave: Dalcídio Jurandir; Belém do Grão Pará; Gastronomia Paraense.

\begin{abstract}
In Belém do Grão Pará, the fourth novel by the marajoara writer Dalcídio Jurandir, much of Pará's traditional gastronomy is described with special attention. From the kitchens of the rubber barons to the street food, it's possible to watch a parade of delicacies that stir the palate, the sight, the touch, and the hearing, between exoticism and tradition.
\end{abstract}

Keywords: Dalcídio Jurandir; Belém do Grão Pará; Paraense gastronomy.

Para inicio de conversa, ele não aceita o rótulo de romancista da Amazônia. - Eu não gosto desse rótulo. Eu sou um escritor marajoara. É mais restrito, mais exato. No entanto, exatamente porque soube aprofundar as realidades humanas da ilha do Marajó e de Belém do Pará, sua obra atravessa essa fronteira. É uma visão de toda a sociedade do extremo Norte. E, nesse sentido, é uma denúncia. (TORRES, 1996, p. 29). 
A cultura brasileira é híbrida e mestiça. A raiz primordial é indígena, mas os brancos colonizadores portugueses impuseram um rei, uma língua e uma fé. Mais tarde o suor e a saudade do Continente Negro se afirmaram no batuque do tambor, na religião animista e nos sabores exóticos. Depois foi a vez dos imigrantes europeus e orientais: novas línguas, novos costumes, novas comidas. Hoje é a vez da tecnologia com os cabos de fibra ótica, as antenas de celular e a internet de alta velocidade. Na região Norte, o ritmo do carimbó, do lundu e das toadas, ou a melodia religiosa dos responsos, das ladainhas e das músicas litúrgicas nas procissões são acompanhados por instrumentos artesanais, pau e corda, metais, e que, mais recentemente, convivem, lado a lado, com os treme-terra e seus repertórios tecnobrega. As igrejas evangélicas convivem com a pajelança, com as garrafadas, os banhos de cheiro e com as benzeduras (RODRIGUES et al., 2006). As ruas de Belém do Pará exalam perfumes de camarão seco, de jambu, de peixe frito com açaí, de caldo de tartaruga.

Belém do Grão Pará (1960), doravante $B G P$, é o quarto volume do chamado "Ciclo do Extremo Norte", produção de autoria de Dalcídio Jurandir (1909 - 1979), antecedida por Chove nos campos de Cachoeira (1941), Marajó (1947) e Três casas e um rio (1958) e sucedida por Passagem dos inocentes (1963), Primeira manhã (1968), Ponte do galo (1971), Os habitantes (1976), Chão dos lobos (1976) e Ribanceira (1978). Nos dez romances, exceção apenas para Marajó, acompanha-se a trajetória do protagonista Alfredo, menino de Cachoeira do Arari que transita entre os espaços da ilha de Marajó e de Belém nos anos 1920.

Em $B G P$ a cidade de Belém é a musa e a meta perseguida pelo garoto Alfredo; a urbe é uma espécie de espaço encantado no qual ele projeta sonhos de uma vida melhor, longe da rotina provinciana de Cachoeira, sua cidade natal. A narrativa apresenta dois núcleos de personagens, socialmente distintos. O primeiro deles é formado pela família Alcântara, os patrões, sob os auspícios de dona lnácia, que comanda o marido Virgílio e a filha Emília, e os empregados Libânia e Antônio, e Alfredo, o qual se torna uma espécie de agregado. O segundo núcleo é formado por um grupo de negros, parentes de dona Amélia, mãe de Alfredo: Mãe Ciana, Magá e as filhas lsaura e Violeta. Os personagens masculinos, irmãos de lsaura, são o verdadeiro elo com os Alcântara e são trabalhadores autônomos ou assalariados.

Cercado por esta galeria de personagens, Alfredo recolhe com sensibilidade cada minúcia da realidade que o circunda: a rotina das 
casas, o ritmo frenético do Mercado Ver-o-Peso, a ruína econômica da aristocracia da borracha, histórias de amor e de lutas políticas, além da exaltação das iguarias de sua terra.

Dalcídio Jurandir era membro da "Academia do Peixe Frito", uma agremiação de treze intelectuais, majoritariamente negros e autodidatas, capitaneada pelo poeta e jornalista Bruno de Menezes (1893-1963). As reuniões da associação ocorriam nas barracas do mercado Ver-o-Peso. Nos encontros regados a cachaça e peixe frito com açaí, o grupo discutia a possibilidade de instauração de uma modernidade literária no Norte e a defesa da negritude; era uma reação àqueles intelectuais da pequena burguesia paraense que se congregavam nos cafés da cidade na década de 1930, à moda parisiense.

Ah! É notável a influência do peixe frito na literatura paraense! Peixe frito é o peixe vendido em postas nos tabuleiros [sic] do Ver-o-Peso ao lado do mercado em Belém. É a comida para quem não deixa almoço comprado em casa. Ao chegar o meio dia, o pobre se tem a felicidade de haver arranjado dois mil réis leva um embrulhinho envergonhado de peixe para casa. [...] A vida literária do Pará tem-se movimentado em torno do peixe frito. Conheço profundamente esse drama. (JURANDIR, 1960, p. 15).

Como enfatizam Nunes e Costa (2016), os "moços" da Academia do Peixe Frito partilhavam com os leitores as preocupações da modernidade em termos de "propor uma inversão do olhar do leitor até então acostumado a ver habitar as páginas dos livros e jornais apenas a 'fina flor' da sociedade da Belle Époque, advinda das classes altas e da gente branca", textos em que se mesclavam as nuances da elite afrancesada às tonalidades da negritude.

Em seu estado natal, Jurandir colaborou com os jornais " $\mathrm{O}$ Imparcial", "Crítica" e "Estado do Pará", e com as revistas "Escola", "Guajarina", "A Semana", "Terra Imatura" e "Novidades". Já no Rio de Janeiro escreveu para os jornais "O Radical", "Diretrizes", "Diário de Notícias", "Correio da Manhã", "Tribuna Popular", "O Jornal”, "Imprensa Popular", e para as revistas "Literatura", "O Cruzeiro", "Vamos Ler!", "Cultura Política". Atuou também nos semanários "A Classe Operária", "Para Todos" e "Problemas".

A opção estética e política de Jurandir pode ser incluída na chamada segunda geração do Modernismo, compreendida didaticamente 
entre 1930 a 1945 e representada principalmente por Jorge Amado (19122001), Rachel de Queiroz (1910-2003), José Lins do Rego (1901-1957), Graciliano Ramos (1892-1953) e Dyonélio Machado (1895-1985). Mesmo assim, por muito tempo a crítica encarou com restrições a obra dalcidiana, como aponta Furtado:

Dalcídio era voltado à reflexão, por isso a reinterpretação da tradição literária existente, tanto em relação à Amazônia, quanto em relação ao país, parece que foi a tônica em seu pensamento. Possivelmente provém dessa tendência dalcidiana de reinterpretação do tradicional em nossas letras a dificuldade em enquadrar a obra Extremo Norte em alguma gaveta rotulada da literatura brasileira. (FURTADO, 2002, p. 102, grifo do autor).

Em $B G P$ Jurandir descreve com especial atenção, dentre outras coisas, as chamadas comidas de rua. A cozinha de rua é aquela expressão do povo e preparada para o povo, típica fórmula da preeminente cultura material, com estreitas ligações com o território, a agricultura, o clima, as estações do ano, com o ambiente social e com a tradição. Se Elliot afirmava que a cozinha é uma das formas de cultura, também aquela produzida nas ruas é um revérbero dessa cultura, menor ou marginal quanto se queira, mas sempre espelho de um modo de consumir e de viver. Exercida na maioria das vezes por ambulantes, seus protagonistas animavam a cena da existência humana daquelas camadas da população que viviam e se contentavam com pouco. São protagonistas de um mundo colorido e compósito, a serviço de um consórcio humano dolente, porém aberto à esperança, à imaginação, ao desejo de existir (e resistir) com seu modo de se alimentar, de consumir, de sobreviver, de pensar.

$\mathrm{O}$ conceito de comida de rua, de uma refeição rápida fora da própria residência, manteve-se e evoluiu em quase todas as sociedades e em muitos países ainda é um forte fator cultural. Por comida de rua entende-se o preparo, exposição, venda e consumo de comida em logradouros públicos e mercados, ao ar livre ou em locais parcialmente fechados, numa relação custo-benefício bastante vantajosa e não menos saborosa do que uma refeição em restaurantes, por exemplo. $\mathrm{O}$ hábito de consumir comidas na rua manteve-se ao longo dos séculos, vindo ao encontro de exigências diversas que se modificaram no decorrer do tempo.

Mercados, ruas e praças: são eles os templos da comida de rua. Os seus sacerdotes-ambulantes são integrantes daquela categoria que La 
Stella (1982, p. 213) considerava entre "as mais beneméritas, coloridas e sonoras que davam vida, gosto e odor a uma cidade". Também as produções escritas desses ambulantes são páginas de história social e econômica porque participam, seguem e até antecipam o progredir da sociedade, mesmo daquela mais humilde, pois priorizam suas necessidades e seus gostos. Nos palcos acima apontados, essa particular tipologia de ambulantes vendedores de comida montava a cenografia de sua atividade com bancadas e vitrines itinerantes: um arsenal de panelas, frigideiras e caldeirões com marcas de grande uso, modestas ferramentas de trabalho, copos, pratos, talheres e cestos. O mundo dos ambulantes vendedores de comida, por mais mísero, marginalizado e rústico que fosse, fazia parte da sociedade do tempo que, na procissão dos homens, pitoresca e dolente, inseria-se no grande romance da vida.

\section{O mercado}

A imagem do Mercado Ver-o-Peso é uma das mais eloquentes de Belém. A abundância de mercadorias, o pregão dos vendedores, o charme das senhoras da aristocracia a comprar a matéria-prima para o preparo de iguarias, as texturas, as cores e os odores, merecem atenção do escritor marajoara. Pereira assim descreve o mercado nos anos 1950:

Pelo seu colorido local, altamente expressivo, misto de doca e de mercado popular, cuja confusão e pitoresco se tornam inesquecíveis, o VER-O-PÊSO [sic] constitui um dos aspectos mais característicos do porto e da cidade de Belém. [...] Pela manhã, bem cedo, as docas do VER-O-PÊSO [sic] tomam, então aspecto festivo. [...] O peixe, o feijão, as frutas, a farinha, as galinhas e as tartarugas, os cachos de bacaba e açaí, os cupuaçus, os cestos de tangerinas, bem como os jacazinhos de abios e os de bacuri, as cordas de caranguejos, as pencas de bananas, as verduras de toda sorte, tudo isso é desembarcado e colocado no chão, ou espalhado sobre mesas toscas para o efeito de ser vendido ao povo. (PEREIRA, 1956, p. 54-55).

Ir ao mercado era o programa de domingo em $B G P$ após a missa na Basílica de Nazaré. 
Seu Alcântara, como um administrador do Mercado, tinha uma visível delícia em escolher demoradamente o melhor peso da carne dominical, a melhor penca de banana na quitanda e as boas alfaces do verdureiro. Ao chegarem ao Ver-o-Peso lhe apeteceu uma tainha fresca e Alfredo via, então, uma nova cidade, agora sem Libânia, meio bruta, que lhe pedia dinheiro em troca de peixes, carnes, frutas e verduras, panelas de mingau, prateleiras de cheiro, dentes de boto, línguas de pirarucu, cascas e raízes, defumações e ninhos de gavião core contra mau olhado, quebranto, contra qualquer gênero de infelicidade. Seu Alcântara, com o seu conhecimento meticuloso dos mercados, conversava com este e aquele peixeiro, examina aqui a barriga da tainha, ali a gurijuba, peixe grande de comer homem. Adiante o monte de pratiqueiras que lembravam a Alfredo os peixinhos nadando em baixo do chalé e em Belém, na panela de barro, nadando no tucupi. (JURANDIR, 1960, p. 87-88).

\section{Alcântara, profundo conhecedor do mercado, detém uma sabedoria e faz das compras um verdadeiro ritual:}

Seu Alcântara hesitava ao ver a pirapema, até que deste peixe mandava pesar um quilo choradinho na balança. Com minuciosa familiaridade, observava: escolhe, remira, revira, cheira, compara, observa aquela peixada toda numa gulosa impaciência de quem logo começasse a devorar a posta da pirapema, a cabeça de gurijuba, as ovas de tainha. Caminhava entre as bancas de peixe, legume e frutas, como um rei das estórias passando em revista os presentes de seus vassalos. (JURANDIR, 1960, p. 88).

Ainda no ambiente do mercado paraense, a atração para o protagonista de $B G P$ é a variedade de farinhas, o multicolorido das frutas tropicais e a presença dos quelônios da Amazônia:

Voltava-se agora para os cestos, fogareiros de barro, bichos, cachimbos, ah, este um, aqui, eu fumava. O gosto de provar de todas as farinhas ali expostas nos paneiros em plena calçada não atingida ainda pela maré. Pôs-se a provar desta, daquela, a amarelinha, a bem torrada, fingindo enfado, competência, exigente no escolher. Cada melancia, aquele ananás, uns muçuãs que deviam estar gordinhos, a tracajá virada, Deus! o doente da pele bebendo mingau no quiosque. Um velhusco, suada a camisa colando nas costas, a bagana na boca, conferia pules de bicho. (JURANDIR, 1960, p. 69). 
A mandioca e a farinha, seu principal subproduto, são consumidas por todas as camadas da população e se apresentam como principal insumo tanto de pratos cotidianos mais simples quanto de outros mais refinados e elaborados. $\mathrm{O}$ seu cultivo, processamento e usos culinários conferem considerável importância histórica, econômica e social à raiz. Não obstante a farinha seja produzida e consumida de norte a sul do Brasil, são obedecidos uma série de critérios culturais na opção por um ou outro tipo, conforme as preferências e tradições locais. Na região amazônica se destaca, além da produção de farinha, aquela do tucupi, líquido amarelado extraído da massa da mandioca ralada e elemento-base de pratos típicos locais.

FIGURA 1 - Mercado Ver-o-Peso. Cartão-postal, s./d.

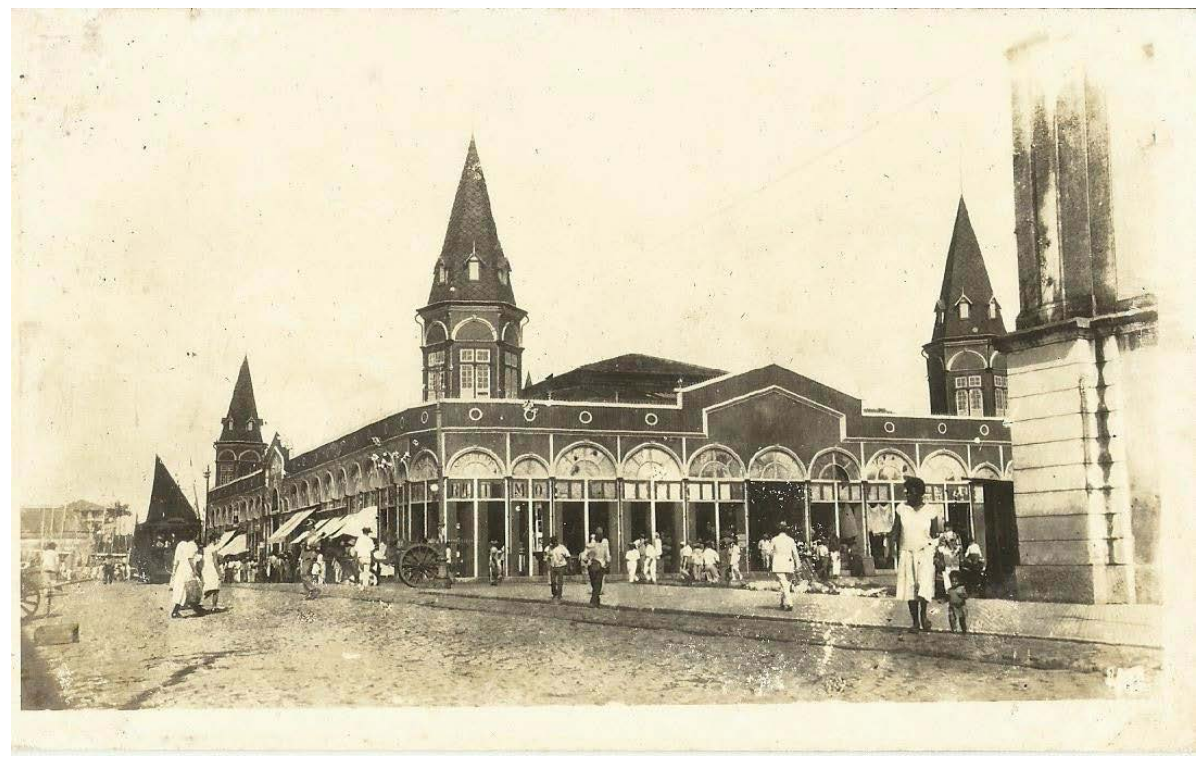

Fonte: acervo do autor.

O vai e vem do mercado, a descrição de suas cores, odores e rumores, a tradição de apregoar as mercadorias fazendo uso de uma linguagem particular, são características do narrador em pauta. Todos esses ingredientes coloridos, cheirosos e até rumorosos, saem do mercado em direção às cozinhas, e é nas cozinhas, santuários alquímicos da transformação do cru em cozido, parafraseando Lévi-Strauss, que as 
matérias-primas se transformam em culinária, patrimônio imaterial e fator que contribui para a construção, com outros tantos elementos culturais, da identidade. Se a cultura alimentar é entendida como "o conjunto de representações, crenças, conhecimentos e práticas herdadas e/ou aprendidas que estão associadas à alimentação e são compartilhadas pelos indivíduos de uma dada cultura ou de um grupo social determinado" (CONTRERAS; GRACIA, 2011, p. 56), o é também aquele conjunto de elementos materiais e imateriais considerados como uma herança compartilhada por uma coletividade.

E das barracas do mercado é que parte para as cozinhas a matéria prima para as refeições diárias e festivas, oportunidade gastronômica em que os insumos se transformam em iguarias:

Seu Virgílio entregava as compras à mulher que lhe devolvia num almoço, mas senhor almoço. Que arte para fazer do pouco um muito, levar à mesa um pirão em que todos se afundavam até rapar o prato; e a pirapema cozida, num molho acariciante e ao mesmo tempo queimoso, de um gosto tão de "quero mais"? Não era pirapema, não. Mas a palavra lida por Alfredo, citada pelo pai, vista no Dicionário: iguaria. Não, iguaria, não. O nome próprio: pirapema no caldo, no pirão, no molho da madrinha mãe. (JURANDIR, 1960, p. 89).

Fraxe afirma que "em âmbito doméstico, os almoços fraternos ocorrem em torno de uma tartarugada, ou de um banquete acrescido de tacacá, de farinha, de bebidas e certamente de açaí, sucos, cremes e sorvetes de frutas da terra, verdadeira farra de gostos, odores e suspiros de prazer" (FRAXE, 2004, p. 186), exatamente como se percebe na descrição do almoço servido na casa da família Alcântara, onde a cozinheira Magá preparava tais quitutes:

Tartaruga nas mãos de Magá não só rendia os sete pratos, como era de se dizer: esta uma tem é parte com Aquele. Na sua mão, até o casco dava gana de se comer. Isto era o que se falava nos Alcântaras, seu Virgílio de olho grandão na conversa, a mãe contando no chalé. E Alfredo roxo que o dia chegasse em que, na Rui Barbosa, aquela fada tirasse de seu fogão o seu sarapatel, o picadinho do peito, o seu guisado de lombo, a farofa no casco, a mixira, o paxicá, que se faz do fígado e farofa.

- Ah, meia tartaruga no centro da mesa, o casco tomando conta da mesa, a gente se servindo. Mas nem eu nem o Senador nem 
ninguém viu melhor tartaruga melhor do que esta da mão da desgraçada desta negra. Parecia que era dum sopro dela, benzida, o Diabo atrás, a tartaruga lá do rio já adivinhando que era Magá que vinha tratar dela. Nem o Senador comeu num casco, como comi na Rui Barbosa, quando os filhos da Magá mandaram ela fazer uma, ah desgraçada! Dava vontade de meter a cabeça dentro do casco, tirar de boca... [...] Muitas vezes batia na Rui Barbosa um chamado: Magá ir preparar uma tartaruga numa dessas casas de branco, pra um banquete político ou chegada dum general. A preta, os jasmins na cabeça, cheirando a cheiro de Mãe Ciana, sua mãe, tinha entrada de gala na cozinha, afastando de sua frente as cozinheiras da casa, já enrolando as mangas: cadê a inocente? E lhe traziam a tartaruga. Mas nunca ninguém arrastava até a boca do corredor, ao pé da sala de jantar, para receber os parabéns, os agrados lá da mesa. "Pra lá com essa pavulage [sic], eras! Repetia e logo entre a criadagem, diante mesmo da dona da casa, soltava a sua adivinha bem salgada, uma das suas de fazer toda a cozinha dizer: "Mas ah! Mas ah!” e era um alívio, agora todos rindo, pois a Magá antes, no fazer a tartaruga, era trombuda, ninguém piasse, que nem pajé em sessão. (JURANDIR, 1960, p. 111-112).

Menezes (2008) afirma que o muçuã (Cinosternum scorpioides), o pequeno quelônio amazônico também conhecido como tartaruga de água doce, é uma iguaria típica do Pará na forma de "casquinho", ou seja, a carne do animal é refogada e servida na sua própria carapaça higienizada e acompanhada de farofa.

Já o paxicá é um picadinho de fígado de tartaruga temperado com sal, limão e pimenta malagueta, e na opinião de Fraxe (2004, p. 180) é um prato que remete "à velha morada dos deuses dessas terras do sem fim", referindo-se às culturas indígenas amazônicas e à sua cosmogonia. Tastevin (1922, p. 649) define o paxicá como "guisado de buxo de tartaruga".

Câmara Cascudo reproduz uma descrição de Spix e Martius que em 1819 conheceram o peixe-boi amazônico e provaram das mixiras: "fazem-se, com a carne e as tripas do próprio peixe-boi, gostosas linguiças (na língua geral, mixiras, do verbo mixire, assar), que são remetidas para Portugal, como especialidade". (CASCUDO, 1968, p. 90). Já no relato oitocentista do cônego Francisco Bernardino de Souza, mixira é descrita como 
a conserva de carne ou peixe em azeite. Depois de cosida em pequenos pedaços a carne ou o peixe vae a frigir. Estando frita, e depois de fria, é depositada em potes cheios de azeite de tartaruga ou de peixe-boi. A melhor mixira é a de peixe-boi ou do tambaquy. Também preparam a mixira com ovos de tartaruga, e com as tartaruguinhas, quando sahem das covas das praias. A palavra mixira, em lingoa geral, quer dizer - assado ou assadura -. (SOUZA, 1873, p 29).

José Veríssimo (1895, p. 79) assevera que a tartaruga é o gado da Amazônia e afirma ainda que paraenses e amazonenses apreciam muito a sua carne, mas que estrangeiros e demais brasileiros tem dificuldade em apreciá-la. Informa, também, que é preparada de vários modos:

Cosida, ensopada ou assada, ou, e é um dos melhores, picada a carne e, servindo de assadeira o próprio peito da tartaruga, assada no forno. Dos miúdos faz-se o guisado conhecido como sarapatel, capitulado por Bates de delicious soup, e que não é sinão, e para melhor, a célebre sopa de tartaruga dos grandes restaurants de Londres e Paris. O sarapatel de tartaruga ou tracajá contentaria o mais fino gourmet. Fazem-o muitas vezes no próprio casco, que aguenta perfeitamente o fogo. No mesmo casco, fazendo de panella, a cosinham ou preparam de outra maneira. $\mathrm{O}$ assado geralmente os quartos inteiros, é feito em espetos de madeira ou no muquém, já descripto. Do fígado, muito saboroso, e carnes gordurosas do peito, regularmente picados em pequenos dados, com pouca farinha d'água, fazem o guisado chamado paxicá. Das diversas partes da carne picada e adubada preparam salsichas ou chouriços. Depois de assada ou moqueada comem-a "de tucupi" isto é fervida no molho feito de mandioca cosida, ou a põem em "mixira" afogando-a na própria banha ou na do peixe-boi e assim dura mezes. (VERÍSSIMO, 1895, p. 79-80).

Segundo Freyre, "a tartaruga [...] constitui sozinha um complexo, dos vários que o indígena transmitiu ao sistema alimentar brasileiro; dela se faz no extremo-norte uma variedade de quitutes, cada qual mais louvado pelos gourmets" (FREYRE, 2003, p. 195).

Em se tratando de uma cidade ribeirinha, o pescado é o soberano das mesas em Belém. Tradicional prato preparado à base de peixe é o escabeche: 
As simples pescadas de escabeche, os pacus no espeto, o mandubé sabrecado, o pato brabo no arroz, as marrecas na grelha, o guisadinho de muçuã, aquele cozidume em geral, de peixes em simples água, sal, chicória, alfavaca e molho de pimenta de cheiro e tucupi. No mocotó, a mãe perdia com a mão de vaca de d. Inácia. Mas na ventrecha do pirarucu, sabia esta ao menos assar? Mas na cabeça de pescada, perdia? O próprio Major Alberto tão desajeitado e impaciente no comer peixe, comia osso por osso, escama, gordura, olho, tudo que saborosamente constituía uma cabeça de pescada tratada pela mão de d. Amélia e levada por essa mesma mão bem dotada a um fogo de lenha ciente do que queria a cozinheira. E amassar o açaí, como a mãe, quem? me mostrem outra? (JURANDIR, 1960, p. 90).

O escabeche deriva do homônimo espanhol escabeche, que por sua vez, derivaria do latim askipitium ou assipitium, pois os romanos já conheciam esse modo de preparar peixes e legumes. Outra vertente sustenta que é do termo árabe $a s-s i k b \tilde{j} j$ que designava uma preparação típica daquela cozinha, reservada ao preparo de carnes cozidas (FRANCESCONI, 1999, p. 570). No Brasil, a escabeche é um clássico exemplo da adaptação de preparos europeus mesclados aos ingredientes e sabores nacionais. Gomensoro (1999, p. 163) reforça a ideia da origem espanhola do prato e comenta que "nasceu de um procedimento antigo de eliminar a cabeça do pescado antes da sua preparação".

Das cozinhas dos barões da borracha para as comidas de rua: se à mesa da aristocracia reinava a tartaruga, nos tabuleiros dos ambulantes reinava o tacacá, comida de raiz indígena:

Alfredo, uma tarde, passou pela Quintino, canto com a S. Jerônimo, no ponto da tacacazeira. Lá estava Magá no seu ofício. Alfredo sabia, todos contavam, a mãe, as duas casas da cidade, que Magá no preparo da tartaruga, não tinha outra. E por fazer tacacá tão bem, merecia anel no dedo, senhora dona no molho do tucupi, no ponto da goma, escolha da pimenta, jambu e camarão, no mexer com a colher de pau a panela de barro e cortar com a colher de sopa o tacacá na cuia e servir. Ali no canto, o ponteiro nas duas, - o relógio da padaria defronte - sentava a sua banca, seus bregueços, os panos alvos, seu asseio. O quarteirão rodeava então

${ }^{1}$ O mandubé (Ageneiosus brevifilis) é um peixe típico da Amazônia, com tamanho médio de 50 centímetros e peso de $2,5 \mathrm{~kg}$. Também é chamado de peixe palmito ou fidalgo. 
ela, um povo, a sua freguesia, tacacá não chegava. Esse ofício dela no canto de rua, aos filhos não agradava tanto. (JURANDIR, 1960, p. 111).

Não se pode negligenciar o fato de que a cozinha popular é uma arte que requer um notável aprendizado e uma constante prática, tanto que a habilidade e o talento das mulheres ao tratar e preparar os alimentos, o saber fazer comida, por muito tempo foi considerado uma espécie de dote, e teve um papel importante na mobilidade social. As mulheres é que preparavam, diretamente ou como coadjuvantes, as refeições dos "senhores", e, de certa forma, tornavam-se também elas um patrimônio popular. Transmitiam o seu saber culinário que, tantas vezes, produzia resultados muito mais saborosos do que a melhor das cozinhas dos ricos, como é o caso, mais uma vez da personagem Magá, que cozinhava para a poderosa família Alcântara e vendia seu tacacá nas ruas.

\section{As ruas e as praças}

A venda e o preparo do tacacá no Norte é, por definição, uma atividade exclusivamente feminina, semelhante à das baianas de acarajé:

Sentada sobre um comum, diante de uma mesa velha e tosca, forrada com uma toalhinha branca, tendo ao lado, num caixote, um fogareiro a carvão e sobre o fogareiro, a panela com tucupi e camarão, e, sobre a mesa, a panela de goma e a cuia de pimenta murupi, e dois ou três montinhos de cuias negras, para servir à freguesia, vive a mulher do tacacá, desde as 15 horas até, em regra, às seis e meia da tarde, e às vezes até tarde da noite distribuindo cuias e cuias de tacacá aos seus fregueses infalíveis. (ARAÚJO, 2003, p. 393).

Preparado com a goma da tapioca e o tucupi, subprodutos extraídos da mandioca, é consumido geralmente ao final da tarde, nas esquinas das principais ruas de Belém, como descrito no romance: as tacacazeiras e as suas barracas compõem a paisagem urbana da cidade. A iguaria é rigorosamente servida e degustada na cuia; não é comida nem bebida: deve ser sorvida, aos goles, num ritual que inclui o uso de um palito para pinçar o camarão e o jambu. 


\begin{abstract}
A língua adormece e o lábio treme levemente. É assim que a velha receita de índio manifesta sua magia: entorpecendo o paladar. Experimente-se qualquer prato da famosa culinária do Pará e se verá que a comida é comida de índio. O tucupi, por exemplo, é pra lá de tribal - nos ingredientes e no preparo. A mandioca é ralada, espremida e depois fervida em fogo lento dias a fio até perder o veneno. Só quando o caldo está bem amarelo, livre de impurezas, é que se lhe acrescenta o aromático e anestesiante jambu - uma plantinha rasteira, considerada medicinal e afrodisíaca. Além do pato assado, o tucupi acompanha qualquer peixe de água doce daqui: tamuatã (cascudo), filhote, pardo, tucunaré e, claro, o pirarucu, o maior peixe de escamas do Brasil. (ROTEIROS..., 1996).
\end{abstract}

Para De Robert e Van Velthem (2008) o tacacá é um prato cuja preparação requer a participação de diferentes especialistas, e não apenas da tacacazeira, a protagonista; nas diversas fases, do aprendizado à venda nas ruas, formam-se redes de troca tecidas ao seu redor onde se superpõem relações comerciais e de parentesco, reconstruídas ou imaginárias: a amizade e a sociabilidade se reforçam no simples ato do seu consumo nas ruas.

É importante recordar que o tacacá e a ornamentação das cuias para o consumo, produzidas em Monte Alegre e Santarém, integram o Inventário Nacional de Referências Culturais (INRC) pelo Instituto do Patrimônio Histórico e Artístico Nacional (Iphan) desde 2015 (INSTITUTO..., 2014).

O preparo e a comercialização das comidas de rua satisfaziam (e ainda satisfazem) muitas das necessidades de consumo, mas, ao mesmo tempo, davam vazão ao instinto de sociabilidade presente em todo o gênero humano e, principalmente, no paraense. Ia-se até a praça ou às ruas, em dias ou não de feira ou de festa, simplesmente para ver e ser visto, para comentar os últimos fatos de crônica, para fofocar, para se distrair e, principalmente, para se sentir cidadão. Por extensão, a rua e a praça tornaram-se sinônimos de gente reunida, de vozes e de encontros.

Os vendedores ambulantes de comida sempre existiram e ainda existem, sobrevivendo numa sociedade opulenta e consumista, mas que ainda consegue preservar esses autores anônimos de uma pequena comédia culinária. Seu papel marginal, mas necessário, era expressivo numa época já desaparecida, e fazia referência a uma coletividade que, nos seus traços mais plebeus, vivia com pouco e de pouco se nutria. 
Daí em diante foi a persistência dele [Lício], macia, meses, diariamente, olhando-a na esquina, a vê-la [Mãe Ciana] nas labutas das casas desses brancos, trabalhar no tacacá, como açaizeira tirando e pondo no portão a bandeirinha encarnada do açaí; ao pé dela na beira da praia entre as ervas e raízes, ouvindo-a na banca do peixe repelir os apresentamentos do peixeiro; na mercearia, mão no cofo, a escolher camarão do Maranhão, aborrecida por não achar um bom para o tacacá da tarde. E atrás dela sempre. Viu-a mingauzeira na festa de Nazaré, no cu da festa, que era atrás do arraial, aquele arraialzinho da maior pobreza, escurinho, longe dos luxos e do muito caro das barracas e das diversões do Largo. (JURANDIR, 1960, p. 264).

Mas os hábitos alimentares não dizem respeito somente à necessidade de nutrição. $\mathrm{O}$ alimento é fundamental para a subjetividade e o sentido de ser. Estando intimamente ligado aos sentimentos mais variados, ele detém a condição de fazer com que tais sentimentos venham à tona, sejam eles positivos ou negativos. Portanto, as práticas alimentares servem para delimitar as fronteiras entre as classes sociais, as regiões geográficas, nações, culturas, períodos do ciclo da vida, religiões, profissões, festas, estações do ano e períodos do dia.

Nas quermesses, por exemplo, outro lugar característico do consumo de comida,

Via Inácia na comitiva de Sua Excia. no arraial de Nazaré quando o Senador, com a sua casaca, a gardênia ao peito, os cortesãos no rabicho, se dirigia à barraca da santa onde era servido daquilo que preferisse: casquinho de muçuã, caranguejo, licores ou sorriso das finas damas da sociedade que eram as piedosas "vendeuses" de Nossa Senhora. Incansável esbelta, d. Inácia conduzia estandartes e puxava o vivório nas passeatas e manifestações. O lemismo tinha sido o seu melhor espartilho. As sestas no recolhimento da Gentil transformavam a senhora. Suas imprecações e sarcasmos viraram num hábito muito seu, quase cordial, o modo divertido de se vingar do infortúnio político e xingar os novos poderosos. Aos poucos foi saboreando novos cuidados menos brilhantes e mais estáveis que eram o senhor preparo da mão de vaca, do cozidão, da feijoada, da maniçoba, do aluá, da gengibirra e da canjica em junho - em junho, seu Virgílio, ah, Inácia restituída - e do peru para o dia do Círio. (JURANDIR, 1960, p. 315). 
Brillat-Savarin (1999, p. 57) define gastronomia como aquele "conhecimento fundamentado de tudo o que se refere ao homem, na medida em que ele se alimenta. Seu objetivo é zelar pela conservação dos homens, por meio da melhor alimentação possível". Mas é correto também afirmar que é uma atitude etnocêntrica considerar somente cozinha e, portanto, "cultura", exclusivamente as práticas alimentares das elites e reduzir à nutrição, portanto à "natureza", a alimentação das classes sociais menos privilegiadas.

Indo mais além, os fazeres culinários mais populares, conservados e transmitidos, praticamente, apenas pela tradição oral, revelam níveis de sofisticação muitas vezes bem maiores que aqueles das elites. Revel comenta que as classes populares, por serem analfabetas na sua imensa maioria, só puderam desenvolver a sua cozinha e transmiti-la durante séculos, por ter sido praticada sem interrupções. Não havia registro escrito de tais práticas: cada geração só podia aprendê-la da precedente, vendo como se fazia através da execução e habilidade (REVEL, 1996, p. 25). A penúria raras vezes substituída por momentos de fartura deu margem ao ingresso desses fazeres culinários no mundo da gastronomia, ou da baixa gastronomia, atividade mais "simples", mas não menos delicada e original. O elemento mais importante aqui é, sem dúvida, a criatividade com a qual, mesmo sendo poucos os recursos econômicos e a indisponibilidade de certos insumos, chega-se a conquistar grandes resultados, em se falando de sabor, é claro.

Comidas populares, comidas de rua, mata-fomes impregnados de gestos antigos, de tradição e de muito sabor. Não era (e continua a não ser) pretensiosa a cozinha de rua, como também não o eram os ambulantes que a praticavam. Cozinha pobre, minuta, quente ou fria que fosse. Coisas simples, alimentos comuns, convenientes e rápidos com o intento de proporcionar um bocado para tonificar o corpo com um toque de gula, entendida mais como um ato de criatividade ao oferecer matérias primas de qualidade.

Assim sendo, os produtos alimentares, além dos objetos e dos conhecimentos utilizados no preparo, transformação e consumo de comida, podem e devem ser identificados como objetos culturais mensageiros da história e da identidade de um grupo social. A alimentação implica em representações e imaginários, envolve escolhas, símbolos e classificações e as diferentes formas de produção e consumo dos 
alimentos desvendam identidades culturais. A literatura desempenha um importante papel nesse sentido, pois como indica Macêdo,

a ideia generalizada de "comida típica regional", que pelo fato de usar ingredientes regionais marcadamente indígenas desde o período colonial passou a ser vista como única, de origem peculiar à região amazônica, para além do campo da literatura modernista paraense. (MACÊDO, 2016, p. 15).

Edificam-se, através de seculares comidinhas de rua, pontos culturais capazes de transformar uma dicotomia em um continuum. Um continuum que favorece uma intensa troca (não apenas comercial) na qual as vozes e olhares se cruzam naqueles locais onde se estabelece o mecanismo de construção da identidade através da invenção do Outro. Como ocorre na fita de Möbius, uma troca contínua entre o interior e o exterior, entre partes de si e partes do Outro.

De certo modo, perdeu-se, hoje, a antiga dimensão do mercado como lugar de alimentação e não apenas de consumo. A beleza de locais como o Ver-o-Peso, onde se pode adquirir hortaliças, peixe, carne, frutas e entender como um povo organiza não apenas a sua alimentação, mas também a sua vida com seus regimes, estilos e tempos. A atual moda do street food está, pouco a pouco, colonizando os mercados históricos. Aqueles em que num tempo anterior eram locais privilegiados de alimentação e convívio urbano, estão se tornando, também graças ao bombardeio midiático e a busca por uma gourmetização, locais turísticos, por excelência. Como afirma Paraense, Belém é

cidade que tem importante título ligado à gastronomia, ainda há muita gente que nem sempre tem o pão de cada dia. Em 2015, Belém foi considerada a Cidade Criativa da Gastronomia, pela Organização das Nações Unidas para a Educação, a Ciência e a Cultura (Unesco). Dos restaurantes de alto padrão às barracas de rua, a capital do Pará tem a culinária como um diferencial. (PARAENSE, 2018).

Partindo da análise de obras e momentos exponenciais da literatura, é possível construir um discurso geral que isole algumas funções e os usos da representação da comida na literatura.

Se por dimensão gastronômica entende-se tudo aquilo que concerne à esfera alimentar, dos alimentos e bebidas aos locais e os 
tempos de preparo, aos contextos nos quais são servidos e consumidos, até as normas aferentes aos usos, costumes e tradições, é possível perceber a presença do alimento, em vários níveis, no interior do texto literário. O alimento pode constituir o objeto, a matéria da representação, condicionando a própria estrutura narrativa; pode oferecer referências a produtos, pratos, costumes característicos de um tempo e de um território determinados. A relação com o alimento também pode se tornar uma forma de comunicação interpessoal, estabelecida por meio de uma linguagem não verbal; pode assumir um significado metafórico, mediando conteúdos diversos e simbólicos; pode, ainda, constituir o campo semântico do qual o autor se serve para fazer escolhas lexicais e estilísticas da sua escritura.

Às funções primárias atribuíveis à esfera alimentar isoladas por Biasin (1991), ou seja, realística, mimética, conotativa e metanarrativa, distintos estudos adicionaram outras funções, enriquecendo o quadro já complexo. Mas, por vezes, também decompondo-o e dividindo-o conscientemente, da complexa polissemia de um texto literário fortemente unitário na sua concepção ou articulado e proteiforme. O alimento, de fato é realmente "um signo sincrético capaz de deflagrar, contemporaneamente, diversos percursos sêmicos" (VAN DEN BOSSCHE, 2000, p. 483).

A primeira função é aquela mimético-realista, ou denotativa, em que o alimento é um dado objetivo inserido na narração para oferecer informações reconduzíveis a precisas coordenadas cronotópicas e histórico-sociais. Em $B G P$, Jurandir, ao citar o sarapatel, a mixira ou o paxicá, ou vice-versa, ou ao não mencionar nenhum prato como no caso do romance Marajó, faz escolhas para conseguir aquele efeito de realidade do qual falava Barthes; nos dois casos o escritor tende à verossimilhança, o que vale dizer, situa de modo coerente e crível, o evento na dimensão espaciotemporal.

A dimensão referencial do alimento como espelhamento da condição política e cultural e como pano de fundo da ação, se faz presente na obra aqui em análise, ao contrastar, por exemplo, as iguarias servidas pela rica família Alcântara com as comidas de rua da cidade de Belém, ou ainda o luxo do serviço da refeição de Barbosa com a parca refeição que consumia: 
Foi um instante, temperou a garganta, curvou-se sobre o prato. Comendo com uma inesperada rapidez, passou a ignorar a comadre, o afilhado, o ganso que entrou, faminto. Alfredo vialhe os óculos pousados na mesa, a mão trêmula no talher, o alvo colarinho gomado, todo o remanescente alinho dos tempos da borracha. Era, na verdade, daquela casa o único habitante, que jantava em companhia de seu gramofone, dos pesados e negros móveis, do ganso que vinha apanhar escassos nacos de pão. Havia na mesa pratos demais, saleiros supérfluos, todo um inútil jogo de louças cercando aquela comidinha rala que seu Barbosa devorava com uma fina pressa e um tanto de aborrecimento. (JURANDIR, 1960, p. 47-48).

Todavia o mesmo trecho também evidencia uma função conotativa, ou seja, aquela através da qual se oferece uma caracterização dos personagens em diversos níveis (social, afetivo, psicológico, econômico), partindo exatamente da análise das comidas e da esfera alimentar. Percebe-se claramente a classe social de Barbosa (pratos demais, saleiros supérfluos, inútil jogo de louças), o aspecto social e até psicológico do personagem (jantava sozinho) e seu nível econômico (todo o remanescente alinho dos tempos da borracha). Na economia do romance em análise, a contraposição entre ricos e pobres, entre burgueses e empregados, inclusive, através da dimensão alimentar é um fil rouge da literatura dalcidiana, de forte engajamento político. Como afirma Mary Douglas,

Um código oferece uma série geral de possibilidades para mandar mensagens particulares: se a comida é tratada como um código, a mensagem que ela transmite se encontrará no esquema das relações sociais que são expressas. A mensagem diz respeito aos diversos graus da hierarquia, inclusão e exclusão, confins e transações através dos limites; a assunção da comida possui de uma componente social, além de uma componente biológica. (DOUGLAS, 1985, p. 165, tradução nossa). ${ }^{2}$

\footnotetext{
${ }^{2}$ Un codice offre una serie generale di possibilità per mandare messaggi particolari: se il cibo è trattato come un codice, il messaggio che esso mette in codice si troverà nello schema di rapporti sociali che vengono espressi. Il messaggio riguarda i diversi gradi di gerarchia, inclusione ed esclusione, confini e transazioni attraverso i confini; l'assunzione del cibo ha una componente sociale oltre a una componente biologica.
} 
O contraponto construído entre o passado de abundância e o presente derrocado remete ao declínio da borracha e, implicitamente, faz uma crítica aos ciclos econômicos monoculturais típicos da economia brasileira, de que resultavam períodos de prosperidade momentânea.

Os nexos entre a alimentação e a identidade se apresentam nas obras de muitos escritores, principalmente daqueles considerados menores ou periféricos, membros de sociedades cuja comida aparece como elemento de identificação e sinal de pertença para aqueles indivíduos, como observa Dalcídio Jurandir:

Por momentos, parecia hesitar entre a arte de sua mãe na cozinha e a de d. Inácia. Esta, vivente em Belém, podia levá-lo a ser injusto com a mãe, vivente em Marajó. D. Inácia fazia pratos do Ceará que era uma novidade para Alfredo, como então comparar? Receava. A mãe podia perder? Sim, a madrinha mãe talvez dispusesse de maiores, melhores e astuciosos recursos de tempero, receita e alimentos, mais desembaraçada no preparo dum jantar de cerimônia, ganhando nos pratos finos. A mãe, porém, valha-nos Deus, que peixe o seu, a pescada desfiada no arroz, sem uma espinha, e no coco? D. Inácia fazia igual? E meu São Benedito, os tucunarés assados, o acari de brasa dormindo no tucupi, a dourada frita com farinha d'água? No pirão de farinha seca, naquele cozidão cearense, tinha sabedoria, algo secretamente da madrinha mãe, dela só, e isso da parte de Alfredo merecia um respeito e um apetite de benza-te Deus, Nas comidas, d. Inácia mostrava o seu avesso, o manso, o acolhedor, a maciez de dentro dela, que ela ocultava, mas temperado com os seus caprichos, gosto de ganhar no bicho, saudade do lemismo, raiva do laurismo, a orgulhosa satisfação de servir bem, exibir a sua competência. Seu Alcântara que o dissesse. O gordo comia como se boiasse a própria mulher. (JURANDIR, 1960, p. 89).

Posta da pirapema, cabeça de gurijuba, ovas de tainha, melancias, ananás, muçuãs e tracajás, tacacá e paxicá são produtos de fundo real, mas também apresentam conteúdo simbólico no romance, o qual vem a ser um verdadeiro compêndio de saberes e sabores. Fala-se de cozinha paraense ou gastronomia paraense na obra dalcidiana?

Do ponto de vista antropológico, as oposições bastante consolidadas pelo senso comum como aquela entre cozinha e gastronomia, na realidade, não ostentam um fundamento objetivo. 
Segundo o entendimento comum, a cozinha seria o conjunto de modos e de técnicas mediante as quais cada sociedade transforma a natureza em alimento. Já a gastronomia seria aquela "arte" de bem preparar os alimentos. Também é recorrente aquela ideia de que somente nas cozinhas complexas e ricas é que se pratica a gastronomia, enquanto na maior parte das sociedades, aquelas menos ricas ou menos refinadas, nas quais viceja uma economia de subsistência, seria impossível a prática de uma "arte". Além de sem fundamento, este modo de entender confunde gastronomia com algumas formas históricas que ela assumiu, principalmente no Ocidente onde só existe gastronomia ao se priorizar e destacar o foie gras, o escargot ou o tiramisù. As preparações mais pobres - ou menos ricas - também se fundam, nos limites consentidos pelos insumos, sobre uma estética e uma "fisiologia do gosto" por nada inferiores àquelas das chamadas grandes cozinhas.

Frequentemente para tornar bons, e não apenas comestíveis determinados alimentos, as chamadas cozinhas simples colocam em ação aquilo que na realidade é a arma decisiva dos grandes chefes de cozinha da atualidade. Por exemplo, o contraponto entre a simplicidade dos ingredientes e as modalidades de cozimento, que transformam um simples pirão de cabeça de peixe em um grande prato, e fazem de um ovo cozido ou de um peixe frito pratos de difícil preparação. São pratos que revelam a habilidade de quem os prepara e a autenticidade de um verdadeiro gourmet que não se deixa levar pela superabundância ou pela redundância dos ingredientes. Na verdade, cada cultura alimentar projeta suas particulares categorias culinárias sobre outras, contribuindo, de certa forma, para que se julgue de maneira etnocêntrica todas aquelas cujos hábitos alimentares são diferentes.

\section{Referências}

ARAÚJO, A. V. Introdução à sociologia da Amazônia. 2. ed. Manaus: Editora Valer: Governo do Estado do Amazonas: Editora da Universidade Federal do Amazonas, 2003.

BIASIN, G. P. I sapori della modernità: cibo e romanzo. Bologna: Il Mulino, 1991.

BRILLAT-SAVARIN, J-A. A fisiologia do gosto. 1. ed. Trad. Paulo Neves. São Paulo: Companhia das Letras, 1999. 
CASCUDO, L. da C. História da alimentação no Brasil. 1. ed. São Paulo: Companhia Editora Nacional, 1968.

CONTRERAS, J.; GRACIA, M. Alimentação, sociedade e cultura. Rio de Janeiro: Fiocruz, 2011.

DE ROBERT, P.; VAN VELTHEM, L.A hora do tacacá. Anthropology of food, S6, dez. 2009. Disponível em: http://journals.openedition.org/ aof/6466. Acesso em: 12 ago. 2018.

DOUGLAS, M. Antropologia e simbolismo: religione, cibo e denaro nella vita sociale. Tradução de Eleonora Bona. Bologna: Il Mulino, 1985.

FRANCESCONI, J. C. La cucina napoletana. Roma: Newton \& Compton Editori, 1999.

FRAXE, T. de J. P. Cultura caboclo-ribeirinha, mitos, lendas e transculturalidade. São Paulo: Annablume Editora, 2004.

FREYRE, G. Casa-grande \& senzala: formação da família brasileira sob o regime patriarcal. 48. ed. Recife: Fundação Gilberto Freyre-Global Editora, 2003.

FURTADO, M. T. Universo derruído e corrosão de herói em Dalcídio Jurandir. 2002. 273 f. Tese (Doutorado em Teoria Literária) - Instituto de Estudos da Linguagem, Universidade Estadual de Campinas, Campinas, 2002.

GOMENSORO, M. L. Pequeno dicionário de gastronomia. Rio de Janeiro: Objetiva, 1999.

INSTITUTO do Patrimônio Histórico e Artístico Nacional (Iphan). Patrimônio Imaterial-PA. Brasília: [s. n.], 2014. Disponível em: http:// portal.iphan.gov.br/pagina/detalhes/515/. Acesso em: 10 ago. 2018.

JURANDIR, D. Belém do Grão Pará. 1. ed. São Paulo: Martins Fontes, 1960.

LA STELLA M. Antichi mestieri di Roma. Roma: Newton \& Compton Editori, 1982.

MACÊDO, S. da C. F. de. A cozinha mestiça: uma história da alimentação em Belém (Fins do século XIX a meados do século XX). 2016. 323 f. Tese (Doutorado em História Social da Amazônia) - Instituto de Filosofia e Ciências Humanas, Universidade Federal do Pará, Belém, 2016. 
MENEZES, B. de. Cozinha do extremo Norte: Pará-Amazonas In: CASCUDO, Luís da Câmara. Antologia da alimentação no Brasil. 2. ed. São Paulo: Global, 2008. p. 61-90.

NUNES, P. J. M.; COSTA, V. M. T. Academia do Peixe Frito: diálogos e intersecções entre literatura, jornalismo e ciências sociais na Amazônia do século XX. In: ENCONTRO ANUAL DA ANPOCS, 40., Caxambú, 2016. São Paulo: ANPOCS, 2016. Disponível em: https://www.anpocs. com/index.php/papers-40-encontro/st-10/st02-8/10533-academiado-peixe-frito-dialogos-e-interseccoes-entre-literatura-jornalismo-eciencias-sociais-na-amazonia-do-seculo-xx/file. Acesso em: 12 ago. 2018.

PARAENSE, R. Belém: contraste entre fartura gastronômica e pobreza. Diário do Pará online, Belém, 15 jan. 2018. Disponível em: https://www. diarioonline.com.br/noticias/para/noticia-479578-belem-contraste-entrea-fartura-gastronomica-e-a-pobreza.html. Acesso em: 15 ago. 2018.

PEREIRA, J. V. da C. Ver-o-Pêso. In: IBGE. Tipos e aspectos do Brasil (Excertos da "Revista Brasileira de Geografia"). 6. ed. Rio de Janeiro: Serviço Gráfico do IBGE, 1956. p. 52-56.

REVEL, J. F. Um banquete de palavras: uma história da sensibilidade gastronômica. Tradução de Paulo Neves. 1. ed. São Paulo: Companhia das Letras, 1996.

RODRIGUES, D. de S. S. et al. Cartografia de Saberes: Abordagem de Pesquisa em Educação Intercultural. In: SEMINÁRIO EDUCAÇÃO INTERCULTURAL, MOVIMENTOS SOCIAIS E SUSTENTABILIDADE, 3, Florianópolis, 2006. Anais [...]. Florianópolis: CED/UFSC, p. 01-14, 2006.

ROTEIROS Turísticos Fiat/Folha Brasil - Belém. Universo Online, 1996. Disponível em: http://www1.uol.com.br/bibliot/turismo/belem. htm. Acesso em: 20 ago. 2018.

SOUZA, F. B. de S. Lembranças e curiosidades do Valle do Amazonas. Pará: Typographia do Futuro, 1873.

TASTEVIN, C. Vocabulario Tupy-Portuguez. Revista do Museu Paulista, São Paulo: Officinas do Diario Official, t. 13, p. 603-763, 1922. 
TORRES, A. Um Escritor no Purgatório. Asas da Palavra, Belém, n. 4, p. 28-30, 1996.

VAN DEN BOSSCHE, B. Il cibo nella narrativa del Novecento: appunti per una tipologia. In: LONERGAN, C. S.; VAN DEN BOSSCHE, B.; BASTIAENSEN, M. (org.). Soavi sapori della cucina italiana. Firenze: Franco Cesati Editore, 2000. p. 483-496.

VERÍSSIMO, J. A pesca na Amazônia. Rio de Janeiro/São Paulo: Livraria Clássica de Alves, 1895. DOI: https://doi.org/10.5962/bhl.title.115390.

Recebido em: $1^{\circ}$ de dezembro de 2018. Aprovado em: 23 de abril de 2019. 